\title{
The Importance and Meaningfulness of Visuals: The Situation for University Students
}

\author{
Melike G. Ekerim ${ }^{1}$, M. Betül Yılmaz ${ }^{2 *}$ \\ ${ }^{1}$ Koç University, Information Technology, Istanbul, Turkey \\ ${ }^{2}$ Yildiz Technical University, Faculty of Education, Istanbul, Turkey
}

\begin{abstract}
The intense use of visual communication tools in today's knowledge and communication era does not mean that visual messages are correctly perceived and communication is appropriately structured. Similarly, it is just an assumption that people from younger generations, who are believed to have high levels of visual literacy, properly perceive the visuals they are exposed to. This study aims to determine whether there is a correlation between university students' visual literacy levels and their skills for comprehending, interpreting, and evaluating visuals as well as between their visual literacy perceptions of themselves and their inclination to visuals and/or text on a web page they visit. More specifically, the study examines whether university students who perceive themselves as individuals with high levels of visual literacy are really equipped with these skills and whether they incline to visuals first or not when they access a web page. In the first phase of the study, which uses a relational survey model, 478 university students were determined as subjects with the stratified sampling method. The second phase was conducted with seven students determined from among the initial sample with the purposeful sampling method. The data for the study was collected with the Visual Literacy Scale developed for university students by Aslan and Nalinci (2014), the Scale for Inclination to Visuals and / or Text on a Web Page, and the Performance Test for Comprehending, Interpreting and Evaluating Visuals. For statistical analysis of the study, normality analysis, exploratory factor analysis and independent groups t-test were used. The findings of the study showed that university students cannot always correctly interpret visuals although they perceive themselves as visually literate individuals. The study also revealed that university students with high levels of visual literacy perception do not recognize visuals first on a web page; however, as their visual literacy levels decrease, they preferably incline to the use of text together with visuals on a web page.
\end{abstract}

Keywords: Higher education, Tertiary students, Visual literacy, Visual preferences.

\section{INTRODUCTION}

Many theories have been developed regarding the importance of visuals as modern culture has become more and more dependent on the presence of visuals in many context (Bamford, 2003), since they allow universally comprehensible and immediate communication of messages. One of these theories is Dual Coding Theory, which was developed by Pavio (1971). According to Pavio, images are remembered more easily than words because images can be recalled through both verbal and visual codes and visual codes are retained relatively longer when compared to verbal codes. Mintzer and Snodgrass (1999) also point out that visuals have remarkably distinctive characteristics that allow them to be uniquely coded in the memory, which can be explained by Baddeley's (1992) Working Memory Theory. According to this theory, text and visuals are processed in the following areas of working memory: visuospatial sketch pad which manipulates visual images, and phonological loop which stores and rehearses verbal information. It is essential that these areas should tally with each other during mental activities due to the importance of retention of information stored in the long-term memory. When we consider this situation from the perspective of Cognitive Load Theory (Sweller, van Merriënboer, \& Paas, 1998), we can see that cognitive load imposed by text in learning environments is lower when these text are accompanied with visuals. Cognitive Theory of Multimedia Learning, which was developed by Mayer (2005) based on the principles suggested in above mentioned theories, claims that presenting information together with visuals and text is more productive when compared to text-only or visual-only presentations since they have the potential to complement each other. In other words, when a visual is associated with a text, information is retained longer when compared to text-only or visual-only presentations (Mayer, 2005).

Corresponding Author e-mail: beyilmaz@yildiz.edu.tr https://orcid.org/0000-0003-4704-189X

How to cite this article: Ekerim MG, YIImaz BM (2022). The Importance and Meaningfulness of Visuals: The Situation for University Students. Pegem Journal of Education and Instruction, Vol. 12, No. 1, 2022, 39-47

Source of support: Nil

Conflict of interest: None.

DOI: 10.47750/pegegog.12.01.05

Received: 21.08.2021

Accepted: 22.11.2021

Publication: 01.01.2022 
Visual input is a dominant factor in perception and memory (Posner, Nissen \& Klein, 1976). Lohr (2008) states that a visual is a type of non-verbal communication and a large amount of information is processed in learning environments. Digital environments in today's world (i.e the Internet, Web 2.0 tools and applications, etc.) involve a lot of visuals in their contents. However, it is necessary to be equipped with certain skills to interpret visuals in order to grasp the intended meaning during communication processes (Stokes, 2002). Text reading skills alone are not enough in today's information communication environments, which are also used intensely in education and these environments should be supported by the use of basic skills such as visual literacy (İşler, 2002; Stokes, 2002).

The concept of "visual literacy" was first used by Debes (1969) and attracted considerable attention from educators due to the effects of television on behaviors and knowledge (İpek, 2003). According to the definition of visual literacy by International Visual Literacy Association (IVLA), a visually literate individual should have the following four basic competencies and skills (Petterson, 1993:140): (a) discriminating visible objects and gleaning meaning from them; (b) effectively creating a static and dynamic visual object in a certain area; (c) comprehending and appreciating other individuals' visual preferences; and (d) conjuring objects in their minds (Brill et.al, 2007).

The related literature shows that the data collection instruments developed in order to determine visual literacy levels of individuals often measure this construct in self-report format (Arslan \& Nalinci, 2014; Bulut, Ulu \& Kan, 2015; Kiper, Arslan, Kıyıcı \& Akgün, 2012; Özsevgeç, Akbulut \& Özsevgeç, 2010; Şahin \& Kıran, 2009; Yeh \& Cheng, 2009). Many studies conducted in Turkey by collecting data in self-report format revealed high levels of visual literacy perception levels (Kocaarslan \& Çeliktürk, 2013; Mert, 2017; Özsevgeç, et.al., 2014; Şahin \& Kıran, 2009; Taşpınar, 2017). In fact, there is a limited number of studies that measure visual literacy levels directly (Avgerinou, 2007; Çimen \& Aygüner, 2018; Farrell, 2013; Turan \& Aslan, 2015; Yeh \& Lohr, 2010). These studies might show that how individuals perceive their own literacy level might not always be in parallel with their real visual literacy levels when data is collected in self-report format.

Prensky (2001) suggested the term "digital native" to define intense use of digital environments by today's generation and their preference for graphics rather than text. The fact that the new generation is introduced to media and visual communication tools at an early age does not guarantee that they are not partial or passive recipients of messages and able to distinguish and grasp intended and valuable information in messages (Avgerinou \& Ericson, 1997; Brumberger, 2011). Thus, their "graphics-first" inclination and "graphical awareness" skills (Prensky, 2001) may not mean that students properly make meaning from these inputs or prefer some other inputs such as text. In other words, living in a visual-rich world may not imply that they acquire visual literacy skills and know how and when to use these skills (Braden, 1996; Felten, 2008) and intentionally prefer visuals.

In light of this information, this study aims to determine whether university students' perceptions about their own visual literacy levels tally with their real performances. In addition, the study tries to explore whether inclinations of university students in digital environments are in favor of visuals or not.

In light of this information, this study aims to determine whether university students' perceptions about their own visual literacy levels tally with their real performances. In addition, the study tries to explore whether inclinations of university students in digital environments are in favor of visuals or not. Accordingly, the research problems of this study were determined as follows:

- Is there a significant relationship between university students' perceptions of their own visual literacy and their skills for comprehending, interpreting and evaluating visuals?

- Is there a significant relationship between university students' perceptions of their own visual literacy and their inclination to visuals and / or text first on a web page they visit?

\section{Method}

\section{Research Design}

This quantitative study uses relational survey method, which aims to determine correlations between two or more variables (Karasar, 2016).

\section{Study Group}

The participants of the study are 478 university students who were determined by using stratified sampling method based on faculty from a population of 14869 students attending a private university in İstanbul and studying at the following faculties in the university: Law, Communication, Business Administration, Architecture, Engineering and Natural Sciences, Health Sciences and Social and Human Sciences. $14 \%$ of the participants are first year students, $29 \%$ second year, $33 \%$ third year and $23 \%$ fourth year. Female participants constitute $60.9 \%$ of the overall study group and the average age for the participants is 21.62 .

More than half of the participants (52\%) used the internet for the first time when they were within the 10-13 age range and one third (37\%) within the 6-9 age range. The average age for the participants in terms of their first experience with the internet is $9.94 .92 .1 \%$ of the participants reported that they spend time in front of a screen (computer, mobile phone etc.) 
every day. Almost half of these students (48\%) stated that they spend 3-5 hours a day in front of a screen. The percentage of the participants who spend $0-2$ hours in front of a screen is $10 \%$.

Table 1 below displays the descriptive analysis of the scores the participants obtained from Visual Literacy Scale, which was administered in order to determine the visual literacy perceptions of the students in the study group.

According to Table 1, the mean scores of students in the study group correspond to "I agree" range for all the factors of the scale and for the overall scale, which indicates high level of visual literacy perception.

In summary, the students in the study group are receiving their education in various disciplines, used the internet for the first time when they were 10 years old in average, spend 3-5 hours in average in front of a screen, visit web pages for different purposes and perceive themselves as "visually literate", which makes them a suitable group for the purposes of the study.

\section{Data Collection Instruments}

Personal Information Form: Prepared by the researchers themselves, this personal information form aims to collect the following data about the participants: age, gender, the faculty they attend, school year, the age when they used the internet for the first time, total time spent daily in front of screen (computer, mobile phone etc.), how frequently and why they visit web pages.

Visual Literacy Scale: One of the data collection instruments of the study is Visual Literacy Scale developed by Aslan and Nalinci (2014) for university students. This 41-item and 5 -point Likert scale has seven factors: "determining visual needs" (4 items), "searching and accessing visual sources" (8 items), "comprehending and interpreting visuals" (5 items), "evaluating visuals and visual sources" (5 items), "using visuals and visual media effectively" (4 items), "designing and creating visuals" (8 items), "considering ethical and legal issues" (7 items). The score to be obtained from the scale ranges between 75 and 375, and high score implies high levels of visual literacy perception. Factor loads were examined by the Varimax rotation technique and explained total variance value of the scale was calculated as $57,201 \%$.

Cronbach Alpha internal consistency coefficient was calculated as .947 in the original study and .922 in the current study. These values clearly show that the scale is highly reliable (Kalayc1, 2014).

Scale for Inclination to Visuals and / or Text on a Web Page: This scale was developed within the scope of the study and aims to determine whether individuals primarily incline to visuals or text when they visit a web page on the internet. To achieve this purpose, the researchers originally prepared 14 items, which involved statements asking individuals to report whether they incline first to visuals or text when they visit a web page. Two sample items from the scale are as follows: "When I visit a web page, I look at visuals first (picture, photograph, diagram, table, video, animation etc.)" and "I cannot interpret a visual without reading the related text". Later, these 14 items were finalized by receiving expert opinion and conducting a pilot study with a group of students attending a state-run university.

The final version of the scale was administered to 478 university students in the study group. According to KaiserMeyer-Olkin (KMO) and Bartlett Sphericity test results, data were found to have sufficient sample size and show normal distribution. Later, exploratory factor analysis was done to the data set and the factor related to "looking at text first on a web page" (8 items) was excluded from the scale since it did not work in the current study, similarly to the experimental study conducted by Schueler, Scheiter, \& Gerjets (2012). This situation implies that students do not only focus on text and they certainly look at visuals as well. When this factor is excluded, two 6-item factors of the scale "Inclination to visual first" and "Inclination to visual and text together" account for $60 \%$ of the total variance.

As for the item reliability of the Scale for Inclination to Visuals / Text on a Web Page, the corrected item-total correlations were calculated first and no other items were excluded from the scale since there were not any items displaying low correlation. Independent t-test was run to determine the significance of the difference between the

Table 1: Descriptive analysis of Visual Literacy Scale scores of the participants

\begin{tabular}{|c|c|c|c|c|c|}
\hline Factors & $n$ & $X \bigotimes$ & $S d$ & Min & Max \\
\hline Determining visual needs & 478 & 4,16 &, 591 & 2,00 & 5,00 \\
\hline Searching and accessing visual sources & 478 & 4,04 &, 564 & 2,13 & 5,00 \\
\hline Comprehending and interpreting visuals & 478 & 4,08 & ,605 & 1,80 & 5,00 \\
\hline Evaluating visuals and visual sources & 478 & 4,02 & ,602 & 2,00 & 5,00 \\
\hline Using visuals and visual media effectively & 478 & 3,77 & ,725 & 1,25 & 5,00 \\
\hline Designing and creating visuals & 478 & 3,96 & ,618 & 1,63 & 5,00 \\
\hline Considering ethical and legal issues & 478 & 3,79 & ,751 & 1,00 & 5,00 \\
\hline Total & 478 & 3,97 &, 505 & 2,41 & 5,00 \\
\hline
\end{tabular}


$27 \%$ groups obtaining the highest and the lowest scores so that it was possible to determine how successfully the scale distinguishes individuals. The results of this test revealed a statistically significant difference between top $27 \%$ and bottom $27 \%$ groups at .001 level of significance. Cronbach Alpha reliability coefficients of the factors were calculated as .586 for the first factor and .714 for the second one. Pallant (2007) suggests that it is probable to perceive low Cronbach Alpha coefficient in scales with lower than 10 items. According to the findings obtained, the scale can be said to be reliable.

The correlation analysis for two factors of the scale revealed a low-level positive correlation at .001 level of confidence. Since both factors are related to visuals on a web page and text is mentioned only in one factor, such a low-level correlation is an expected finding.

Performance Test for Comprehending, Interpreting and Evaluating Visuals. Within the scope of the study, a performance test was developed to measure how university students comprehend, interpret and evaluate visuals. To achieve this purpose, 3 visuals were designed under the supervision of a designer working in the field of visual communication: (i) Multiple frames + words, (ii) multiple frames with no words, and (iii) single frame with no words. Figure 1 below presents two of these visuals.

The items in the factors "Comprehending and Interpreting Visuals" and "Evaluating Visuals and Visual Sources" in Visual Literacy Scale were taken into consideration while developing these visuals. Some of these items are as follows: "I can express my opinion about a visual", "I can find out the relationships between different visuals", "I can recognize sexual identity, and ethnic, cultural and social representations in a visual" and "I can read and interpret meta-knowledge and related text in order to comprehend a visual".

Experts from the field of Visual Communication Design (3), Communication Design and Management (1) and Educational Technologies (2) were consulted to evaluate the extent to which these visuals are appropriate in terms of visual quality, stories and to what extent they tally with the items in the scale. The visuals were finalized through revisions according to the feedback received. The comments provided by a group of university students in the pilot study who are not in the study group showed that these visuals convey the intended message effectively.

In the next phase, the researchers developed a performance test involving open-ended and closed-ended questions in order to measure the participants' skills for comprehending, interpreting and evaluating visuals. The test starts with the introduction of visuals which is followed by leading questions. Later, some drill questions are used, when necessary, to reveal events, situations and feelings that the participants are expected to disclose. Drill questions are prepared in order to ask the participants when they fail to reply to leading questions or provide a clear reply (Harrell \& Bradley, 2009). The content validity of this test was achieved by receiving expert opinion and calculated as 0.99 by using the Lawshe technique.
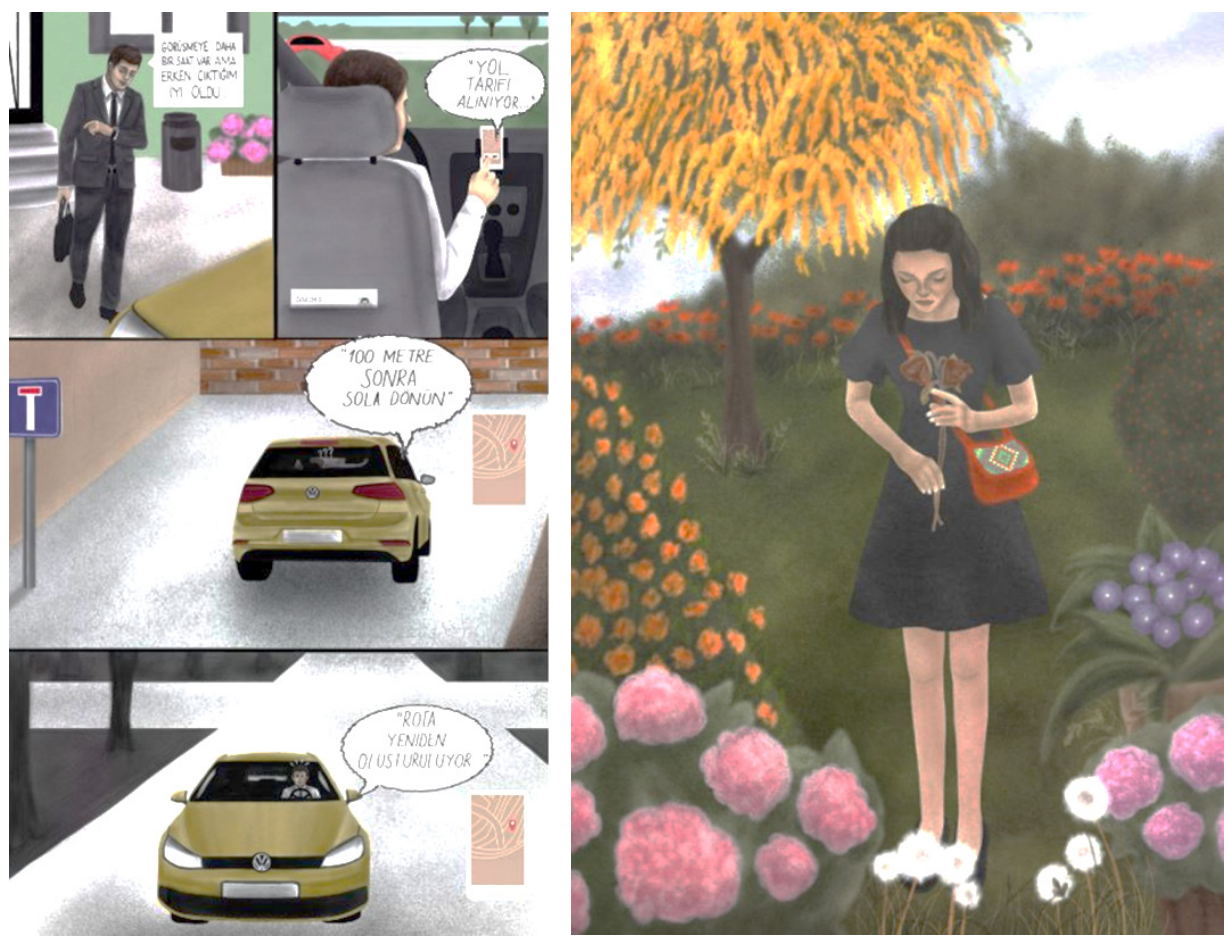

Fig. 1: Sample visuals from the performance test for comprehending, interpreting and evaluating visuals. 
Tally diagram was used while scoring this test. In this diagram, 2 points were given when students directly expressed what they inferred from the visuals and 1 point when they expressed such inferences after a sort of guidance. When students failed to express any inferences, the point given was 0 . The highest possible point to be obtained from the performance test is 132 and high score means high level of visual literacy.

\section{Data Collection}

Prior to the data collection phase, the researchers applied to the Academic Ethical Committee of the state-run university where they work and took the necessary approval to conduct the study. The data were collected from 484 students attending a private university in İstanbul by getting their permission for voluntary participation. The data obtained from six students were excluded from the analyses due to missing information and providing careless and insincere responses. In order to find an answer to first research question, seven students, who received high scores and the scores lower than the average in Visual Literacy Scale were determined by using criterion sampling method, which is a purposeful sampling method. Finally, the performance test data set was prepared by using tally diagrams through the transcriptions of voice recordings taken during the performance test. Necessary permissions were taken for the voice recordings prior to the performance tests.

\section{Data Analysis}

"IBM SPSS Statistics 24" software was used for the statistical analyses in the study. As for the normality analyses of the data set, mean, mod, median, skewness and kurtosis values and significance values of Kolmogorov-Smirnov test were calculated. KMO and Barlett spherical test results were used to determine to what extent the data set was appropriate for explanatory factor analyses. Similarly, Varimax vertical rotation was used in the factor analysis so that factors could be interpreted more easily. As for the item reliability analysis, item-total correlations were used while t-test for independent group was preferred for the mean scores of $27 \%$ highest score group and $27 \%$ the lowest score group for item discrimination. The correlation between data sets was determined by using Pearson correlation analysis. The confidence interval was preferred as .005 in the study.

As for the statistical analyses of the second research problem of the study, the performance test was scored by using MS Excel program. Non-parametric tests were found to be appropriate for these seven students and Spearman Rho Correlation test was applied accordingly.

\section{FINDINGS}

Findings regarding the First Research Problem. In order to find an answer to the first problem of the research, which is "Is there a significant relationship between university students' perceptions of their own visual literacy and their skills for comprehending, interpreting and evaluating visuals?", the data were collected from 7 students who were determined through criterion sampling method from the students who have low, medium and high levels of visual literacy perception and volunteered to take the performance test. The participants were first asked the following questions to determine their skills for comprehending, interpreting and evaluating visuals: "What do you see in this visual?" "What can you tell me about this visual?" and later the drill question "What is happening in this visual?". Later, whether they can make inferences about visuals or not was scored by using the tally diagram. The demographic information about the participants and descriptive analyses of the scale are displayed in Table 2 below.

According to the findings displayed in Table 2, students' visual literacy perceptions do not tally with their performances while comprehending, interpreting and evaluating visuals. Indeed;

- The students coded as S1, S2 and S4, who have high performances in comprehending, interpreting and evaluating visuals (81, 104 and 88 respectively) also

Table 2: Demographic information about the participants and their scale and performance test scores

\begin{tabular}{|c|c|c|c|c|c|c|c|c|c|}
\hline Code & Gender & Age & School year & $\begin{array}{l}\text { Perception for } \\
\text { Comprehending } \\
\text { and interpreting } \\
\text { visuals }\end{array}$ & $\begin{array}{l}\text { Perception } \\
\text { for evaluating } \\
\text { visuals and } \\
\text { visual sources }\end{array}$ & $\begin{array}{l}\text { Visual literacy } \\
\text { perception }\end{array}$ & $\begin{array}{l}\text { Inclination to } \\
\text { visual first }\end{array}$ & $\begin{array}{l}\text { Inclination to } \\
\text { visual and text } \\
\text { together }\end{array}$ & $\begin{array}{l}\text { Performance } \\
\text { Test score } \\
\text { (Max 132) }\end{array}$ \\
\hline S1 & M & 20 & 2 & 5,00 & 4,80 & 4,95 & 3,67 & 2,33 & 81 \\
\hline S2 & F & 20 & 3 & 5,00 & 5,00 & 4,90 & 4,33 & 1,00 & 104 \\
\hline S3 & $\mathrm{F}$ & 20 & 2 & 4,60 & 5,00 & 4,78 & 2,33 & 1,67 & 51 \\
\hline S4 & M & 20 & 1 & 4,00 & 4,40 & 4,12 & 4,00 & 2,33 & 88 \\
\hline S5 & M & 22 & 3 & 3,20 & 2,80 & 3,12 & 2,67 & 2,33 & 94 \\
\hline S6 & M & 20 & 2 & 2,60 & 2,60 & 3,07 & 4,00 & 2,67 & 72 \\
\hline S7 & M & 21 & 4 & 5,00 & 4,60 & 4,76 & 2,67 & 3,00 & 57 \\
\hline Mean & & & & & & 29,7 & & & 78,14 \\
\hline
\end{tabular}


have high levels of visual literacy perceptions (4.95, 4.90 and 4.12 respectively).

- The performance of the student coded as S5 in comprehending, interpreting and evaluating visuals is 94 and he has medium level of visual literacy perception (3.12).

- The students coded as S3 and S7, who have low performances in comprehending, interpreting and evaluating visuals (51 and 57 respectively) have high levels of visual literacy perceptions (4.78 and 4.76 respectively).

- The student coded as S6 has medium level of performance in comprehending, interpreting and evaluating visuals (72) and medium level of visual literacy perception (3.07).

The participants' performance test scores and the findings of Spearman Rho correlation analysis done for their visual literacy perceptions are presented in Table 3 below.

As seen in Table 3 , there is not a statistically significant difference between students' performance test scores and the related factors of Visual Literacy Scale.

Findings regarding the Second Research Problem. The second problem of the current study is "Is there a significant relationship between university students' perceptions of their own visual literacy and their inclination to visuals and / or text first on a web page they visit?" The analysis done on this data set showed that the participants' scores from Visual Literacy Scale and Scale for Inclination to Visual / Text on a Web

Table 3: Findings regarding Spearman Rho correlation analysis between related visual literacy scale factors, inclinations and performance test scores

\begin{tabular}{|c|c|c|c|}
\hline Variables & $n$ & $r$ & $p$ \\
\hline $\begin{array}{l}\text { Performance test score } \\
\text { Perception about comprehending and } \\
\text { interpreting visuals }\end{array}$ & 7 & .519 & .233 \\
\hline $\begin{array}{l}\text { Performance test score } \\
\text { Perception for evaluating visuals and visual } \\
\text { sources }\end{array}$ & 7 & .216 & .641 \\
\hline $\begin{array}{l}\text { Performance test score } \\
\text { Visual literacy perception }\end{array}$ & 7 & .321 & .482 \\
\hline
\end{tabular}

Table 4: Findings of Pearson correlation analysis between inclinations to visuals first on a web page and the related visual literacy scale factors

\begin{tabular}{llll}
\hline Variables & $n$ & $r$ & $p$ \\
\hline $\begin{array}{l}\text { Inclination to visuals first on a web page } \\
\begin{array}{l}\text { Perception of comprehending and } \\
\text { interpreting visuals }\end{array}\end{array}$ & .034 & .461 \\
$\begin{array}{l}\text { Inclination to visuals first on a web page } \\
\begin{array}{l}\text { Perception of evaluating visuals and visual } \\
\text { sources }\end{array}\end{array}$ & 478 & .068 & .140 \\
$\begin{array}{l}\text { Inclination to visuals first on a web page } \\
\text { Visual literacy perception }\end{array}$ & 478 & .087 & .059 \\
\hline
\end{tabular}

Page have a normal distribution. Accordingly, the researcher decided to do Pearson correlation analysis, in which total score from Visual Literacy Scale and its two study-related factors (Comprehending and interpreting visuals, evaluating visuals and visual sources) were used. Since other factors were not directly related, they were ignored in this research question. The findings of Pearson correlation analysis are displayed in Table 4 and Table 5 below.

The findings displayed in Table 4 show that there is not a statistically significant difference between "Inclination to Visual First" factor and Visual Literacy Scale and its factors. On the other hand, Table 5 shows a statistically negative ( $\mathrm{r}=-$ ,131; r=--234; r=-,110) significant low-level difference between overall scale and its "Inclination to visuals and text together" factor and "Comprehending and Interpreting Visuals" and "Evaluating Visuals and Visual Sources" factors.

\section{Discussion}

This study was conducted with a group of university students who have high levels of visual literacy perception. Seven students from this group were given the performance test, whose maximum score is 132 , and they scored 78 points in average while the highest score was 104 . This finding clearly indicates that the participants can comprehend, interpret and evaluate visuals at a moderate level. Although the related literature includes some studies reporting that students have high levels of visual literacy (Kocaarslan \& Çeliktürk, 2013; Mert, 2017; Özsevgeç et. al, 2010; Taşpınar, 2017), the studies carried out by using direct performance often reveal that students have low or medium level visual literacy (Doğru, 2014; Çelik \& Çekiç, 2014; Farell, 2013; Katıranc1, 2014; Matusiak, Heinbach, Harper \& Bovee, 2019; Turan \& Aslan, 2015).

The fact that students live in a visually rich world and interact with visuals in an interactive environment might not increase their visual literacy skills as it is claimed in the once popular "digital native" myth (Matusiak et. al, 2019). Indeed,

Table 5: Findings of Pearson correlation analysis between inclination to text and visual together on a web page and related visual literacy scale

\begin{tabular}{|c|c|c|c|}
\hline Variables & $\mathrm{n}$ & $\mathrm{r}$ & $\mathrm{p}$ \\
\hline $\begin{array}{l}\text { Inclination to visual and text together } \\
\text { on a web page } \\
\text { Perception about comprehending and } \\
\text { interpreting visuals }\end{array}$ & 478 & $-.235^{\star \star}$ & .000 \\
\hline $\begin{array}{l}\text { Inclination to visual and text together } \\
\text { on a web page } \\
\text { Perception about evaluating visuals and } \\
\text { visual sources }\end{array}$ & 478 & $-.110^{*}$ & .016 \\
\hline $\begin{array}{l}\text { Inclination to visual and text together } \\
\text { on a web page } \\
\text { Visual literacy perception }\end{array}$ & 478 & $-.130^{\star *}$ & .004 \\
\hline
\end{tabular}


some research does not reveal any difference between young people and adults in terms of recalling information when visuals and text are used together (Bol, Weert, Loos, Bergstrom, Bolle \& Smets, 2016; Nguyen, van Weert, Bol, Tytgat, van de Ven \& Smets, 2017).

The findings regarding the first research question indicate that students' real visual literacy levels are not parallel with how they perceive themselves. There are students who perform poorly despite their high levels of visual literacy perception or vice versa while some students perform in parallel with their visual literacy perceptions. No correlation was found between students' perceptions of their visual literacy and their performances in comprehending, interpreting and evaluating visuals. In the light of these findings, it was concluded that university students may fail to interpret visuals properly although they perceive themselves as "visually literate" individuals.

This finding is consistent with the findings obtained in similar studies. For instance, Çimen and Aygüner (2018) found that students display poor performances despite their high levels of visual mathematics literacy perceptions. Also, Farrell (2013) focused on measuring performance-based visual literacy and reported that pre-service teachers, in fact, have low levels of visual literacy skills. Similarly, Turan and Aslan (2015) concluded that pre-service history teachers have poor skills in analyzing visuals. These studies indicate that self-report studies may reveal that an individual's real visual literacy level and his perception about his visual literacy do not tally with each other, which implies that we should be skeptical about the studies that are not performance-based.

The findings regarding the second problem of the study show that students generally incline to visuals when they look at a web page and inclination to visuals and text together is relatively lower. No studies reported that students with high levels of visual literacy perception first incline to visuals on a web page. Accordingly, university students with high levels of visual literacy perception do not primarily incline to visuals on web pages.

On the other hand, a low-level negative correlation was found between students' visual literacy perceptions and their inclination to visual and text together on a web page. Accordingly, it might be concluded that the students who incline to visual and text together on a web page have lower levels of visual literacy perceptions; in other words, as visual literacy perception levels decrease, inclination to visual and text together on a web page increases as expected. In short, high levels of visual literacy perception do not entail primary recognition of visuals, which can be explained by the fact that students do not really have the visual literacy level they perceive. Indeed, students who do not find themselves competent enough in terms of visual literacy need a text to support visuals on web pages.

\section{Conclusion and Suggestions}

The results of this study demonstrate the importance of proper use of visuals in teaching environments in terms of students' visual preferences. The use of visuals that are not sufficiently supported with a text in teaching materials, especially on educational web pages, might be a disadvantage for students who prefer to see visuals and text together and cannot properly read and interpret visuals. Clark and Lyons (2011) define "visual" in educational context as "visual expression of knowledge in a way to increase learning and performance". Visuals provide an effective support for learning, which requires a complex mental process, because it is quite challenging to introduce continuously increasing volume of knowledge only through words and to express a non-verbal concept verbally (Brill, Kim \& Branch, 2007; İşler, 2002; Pettersson, 2007). Visual elements are essential in terms of designing environments that might help educators to improve students' mental skills and make learning more meaningful (Sanalan, Sülün \& Çoban, 2007); however, this implementation should be planned carefully (Stokes, 2002). Indeed, Turan and Aslan (2015) suggest that inadequate analysis of visuals occurs due to their integration merely as decorative elements while they are used for educational purposes. Matsuiak et al. (2019) even point out that students see text as the main source of information and ignore visuals since they are not competent in choosing, interpreting and evaluating them.

In this respect, it is quite essential to take into consideration the presence of students who do not have a sufficient level of visual literacy and to apply multi-modality, which means bringing visuals and text together according to the multienvironment principles. Therefore, the first suggestion based on the findings of this study is the use of multi-environment principles while designing learning environments. Mayer (2003) suggests the use of visuals and text together since learning occurs when words and visuals provided for students are carefully structured and claims that presenting visual and text together is likely to enhance learning. Similarly, Mayer and Anderson (1991) found that verbal information accompanied with visuals is more effective in problem solving than providing first verbal information and later visual or providing only verbal information or only visual. Therefore, it might be said that supporting visuals with text in digital environments appropriately is essential for incompetent individuals even though they have high levels of visual literacy perceptions. When this situation is considered in terms of individual differences, it might be a factor helping educators to reach individuals with different learning styles.

Secondly, it is suggested that visual literacy education should be considered as an important component of education even at basic education levels. Visual literacy education will play a significant role when technology allows more effective communication in the modern world (Heinich, Molenda, \& 
Russell, 1989). Visual literacy refers to skills that are not taught directly but acquired through practice and experienced under the supervision of a guide (Smaldino, Lowther, \& Russell, 2012; Stokes, 2002; Y1lmaz, 2017) and this interdisciplinary field is also multi-factorial (Avgerinou \& Pettersson, 2011). An important way for educators at every level of education to provide such a guidance is to be role model through the visuals they present to their students and to do regular practices focusing on comprehending and interpreting visuals. The third suggestion based on the findings of the study is that education faculties should take necessary steps to educate pre-service teachers as a visual literate individual.

Only a limited number of university students' visual literacy levels were measured in this study. Finally, similar studies should be carried out with more students at different levels of education so that we can understand the current situation better.

\section{References}

Arslan, R., \& Nalinci, G. Z. (2014). Development of visual literacy levels scale in higher education. Turkish online journal of educational technology, 13(2), 61-70.

Avgerinou, M. D. (2007). Towards a visual literacy index. Journal of Visual Literacy, 27(1), 29-46. Doi: 10.1080/23796529.2007.11674644

Avgerinou, M. D., \& Pettersson, R. (2011). Toward a cohesive theory of visual literacy. Journal of visual literacy, 30(2), 1-19. Doi: 10.1080/23796529.2011.11674687

Avgerinou, M., \& Ericson, J. (1997). A review of the concept of visual literacy. British journal of educational technology, 28(4), 280-291.

Baddeley, A. D. (1992). Working memory. Science, 225, 556 - 559. Doi:10.1126/science.1736359

Bamford, A. (2003). The visual literacy white paper. Uxbridge: Adobe. https://www.aperture.org/wp-content/uploads/2013/05/visualliteracy-wp.pdf

Bol, N., van Weert, J. C., Loos, E. F., Bergstrom, J. C. R., Bolle, S., \& Smets, E. M. (2016). How are online health messages processed? Using eye tracking to predict recall of information in younger and older adults. Journal of health communication, 21(4), 387396. Doi: 10.1080/10810730.2015.1080327

Braden, R. A. (1996). Visual literacy. Handbook of Research for Educational Communications and Technology, 3(5), 491-520.

Brill, J. M., Kim, D., \& Branch, R. M. (2007). Visual literacy defined - the results of a delphi study: Can IVLA (operationally) define visual literacy? Journal of visual literacy, 27(1), 47-60. Doi: $10.1080 / 23796529.2007 .11674645$

Brumberger, E. (2011). Visual literacy and the digital native: An examination of the millennial learner. Journal of visual literacy, 30(1), 19-47. Doi: 10.1080/23796529.2011.11674683

Bulut, B., Ulu, H., \& Kan, A. (2015). Multimodal literacy scale: a study of validity and reliability. Eurasian journal of educational research, 61, 45-60. Doi: 10.14689/ejer.2015.61.3

Çelik, G., \& Çekiç, O. (2014). Pre-service Turkish language arts teachers' views on their visual literacy skills. Journal of theory and practice in education, 10(4), 840-862.
Çimen, E. E., \& Aygüner, E. (2018). An analysis of eight grade students' self-efficacy perception of visual mathematics literacy and their actual performance. İlköğretim online, 17(2), 675696. Doi: 10.17051/ilkonline.2018.419026

Clark, R. C., \& Lyons, C. (2011). Graphics for Learning: Proven Guidelines for Planning, Designing, and Evaluating Visuals In Training Materials. San Fransisco: Pfeiffer.

Debes, J. L. (1969). The Loom of Visual Literacy: An Overview. Audiovisual instruction, 14(8)25-27.

Doğru, A. G. (2014). The effect of visual arts course on the development of visual literacy skills of high school students. Akdeniz sanat, 11(21), 45-63.

Farrell, T. A. (2015). Visual literacy (VL) in teacher preparation: Measurement to direction. Journal of Visual Literacy, 34(1), 89-104. Doi: 10.1080/23796529.2015.11674724

Felten, P. (2008). Visual literacy. Change: The magazine of higher learning, 40(6), 60-64. Doi: 10.3200/CHNG.40.6.60-64

Harrell, M. C., \& Bradley, M. A. (2009). Data collection methods. Semi-structured interviews and focus groups. Santa Monica: Rand National Defense Research Institute.

Heinich, R., Molenda, M., \& Russell, J. D. (1989). Instructional media and the new technologies of instruction. Macmillan.

İpek, İ. (2003). Bilgisayarlar, görsel tasarim ve görsel öğrenme stratejileri [Computers, Visual Design and Visual Learning Strategies]. Turkish online journal of educational technology, 2(3), 68-76.

İşler, A. Ş. (2002). Günümüzde görsel okuryazarlık ve görsel okuryazarlık eğitimi [Visual literacy and visual literacy education today]. Journal of Uludag university faculty of education, 15(1), 153-161.

Kalaycı, Ş. (2014). SPSS Uygulamalı çok değişkenli istatistik teknikleri [SPSS applied multivariate statistics techniques]. Ankara: Asil Yayın Dağıtım.

Karasar, N. (2016). Bilimsel araştırma yöntemi: kavramlar, ilkeler, teknikler [Scientific research method: concepts, principles, techniques]. Ankara: Nobel Yayın Dağıtım.

Malini Mittal Bishnoi. "Flipped classroom and digitization: an inductive study on the learning framework for 21st century skill acquisition". Journal for Educators, Teachers and Trainers, 11, 1, 2020, 30-45. doi: 10.47750/jett.2020.11.01.004

Katıranc1, M. (2014). Inspection of visual perception levels of Gazi University students. International journal of Turkish education science, 2014(3), 1-17.

Kiper, A., Arslan, S., Kıyıc1, M., \& Akgün, Ö. E. (2012). Visual literacy scale: the study of validity and reliability. The Online Journal of New Horizons in Education, 2(2), 73-83.

Kocaarslan, M., \& Çeliktürk, Z. (2013). Determination of visual literacy competencies of the students of education faculty. Bartın University Journal of Faculty of Education, 2(2), 344-362. Doi: 10.14686/201321994

Matusiak, K. K., Heinbach, C., Harper, A., \& Bovee, M. (2019). Visual literacy in practice: Use of images in students' academic work. College \& Research Libraries, 80(1), 123.

Mayer, R. E. (2003). The promise of multimedia learning: using the same instructional design methods across different media. Learning and instruction, 13(2), 125-139. Doi: 10.1016/S09594752(02)00016-6

Mayer, R. E. (2005). Cognitive theory of multimedia learning. The Cambridge handbook of multimedia learning, 41, 31-48. 
Mayer, R. E., \& Anderson, R. B. (1991). Animations need narrations: An experimental test of dual coding hypothesis. Journal of educational psychology. 83(4), 484-490.

Mert, E. L. (2017). Visual literacy proficiency of 6th and 8th grade students. International Journal of Languages' Education and Teaching, 5(1), 255-266. Doi: 10.18298/ijlet.1702

Mintzer, M. Z., \& Snodgrass, J. G. (1999). The picture superiority effect: Support for the distinctiveness model. The American Journal of Psychology, 112(1), 113.

Özsevgeç, T., Akbulut, H., \& Özsevgeç, L. C. (2010). Determination of visual literacy of preservice teachers. Journal of Turkish Science Education, 7(3), 29-41.

Paivio, A. (1971). Imagery and verbal processes. New York: Holt, Rinehart \& Winston.

Pallant, J. (2007). A step by step guide to data analysis using SPSS for windows version 15. New York: McGraw Hill.

Pettersson, R. (1993). Visual information. Educational technology. New Jersey: Englewood Cliffs.

Posner, M. I., Nissen, M. J., \& Klein, R. M. (1976). Visual dominance: an information-processing account of its origins and significance. Psychological Review, 83(2), 157.

Prensky, M. (2001). Digital natives, digital immigrants part 2. On the horizon, 9(6), 2-6.

Şahin, Ç., \& Kıran, I. (2009). Evaluation of the visual literacy levels of prospective teachers according to their perceptions. Dumlupinar University, Journal of Social Sciences, 23, 77-90.

Sanalan, V. A., Sülün, A., \& Çoban, T. A. (2007). Visual literacy. Erzincan University Journal of Education Faculty, 9(2), 33-47.
Schueler, A., Scheiter, K., \& Gerjets, P. (2012). Verbal descriptions of spatial information can interfere with picture processing. Memory, 20(7), 682-699. Doi:10.1080/09658211.2012.693935

Smaldino, S. E., Lowther, D. L., \& Russell, J. D. (2012). Instructional technology and media for learning. Boston: Pearson.

Stokes, S. (2002). Visual literacy in teaching and learning: A literature perspective. Electronic Journal for the Integration of technology in Education, 1(1), 10-19.

Sweller, J., van Merriënboer, J. J. G., \& Paas, F. G. W. C. (1998). Cognitive architecture and instructional design. Educational Psychology Review, 10, 251-296. Doi:10.1023/A:1022193728205

Taşpınar, Ş. E. (2017). Determination of visual literacy levels of visual art teacher candidates. Erzincan University Journal of Education Faculty, 19(2), 321-334. Doi: 10.17556/erziefd.298455

Turan, İ., \& Aslan, H. (2015). Teacher Candidates' Analysis Levels of Historical Images. Turkish History Education Journal, 4(2), 87-112.

Yeh, H. T., \& Cheng, Y. C. (2010). The influence of the instruction of visual design principles on improving pre-service teachers' visual literacy. Computers \& Education, 54(1), 244-252. Doi: 10.1016/j.compedu.2009.08.008

Yeh, H. T., \& Lohr, L. (2010). Towards evidence of visual literacy: assessing pre-service teachers' perceptions of instructional visuals. Journal of Visual Literacy, 29(2), 183-197. Doi: 10.1080/23796529.2010.11674680

Yilmaz M. B. (2017). Visual literacy in the context of educational technologies (in Educational Technology Readings ed. H.F. Odabaş1, B. Akkoyunlu, A. İşman), 165-182. Sakarya: PEGEM. 